\title{
Space and Emotion: Building to Feel
}

\author{
Margrit Pernau* \\ Max Planck Institute of Human Development
}

\begin{abstract}
Emotions are not only expressed but also learned through the body. The body is not the opposite of culture, but a site where culture is played out. This requires a new emphasis on space and spaces. Bodies are necessarily situated in space, and they bear the imprint of the spaces they are moving through and have moved through. Mediated by the body and its senses, different spaces become linked to different emotions. This relation is neither random, nor is it given once and for all: the connection between an emotion and a particular space can change over time, and the same spaces can trigger off vastly divergent emotions in various people. This article discusses the importance of material objects in shaping emotions; it suggests temporalization as the central category to link materiality with knowledge and practices. It then proceeds to a number of case studies related to the built environment of Delhi to show what such an investigation could look like.
\end{abstract}

Emotion studies for a long time have been caught in the nature - nurture debate. ${ }^{1}$ Emotions were either linked to the body, and hence perceived as universal and unchanging, or they were claimed as learned over the course of life and hence marked by cultural difference. This division was then played out in the discussion of whether life sciences or anthropology (and later cultural studies) were to be the leading disciplines in the investigation of emotions. ${ }^{2}$ In an attempt at overcoming this increasingly unproductive dichotomy, recent debates have foregrounded the body. The body they investigated, however, was no longer the universal body of life sciences. Instead, they took up development in gender and body studies, which had already foregrounded the ways each body is marked and produced by historically contingent experiences; these experiences in turn were seen as socially and culturally mediated. Emotions thus are not only expressed but also learned through the body. The body is not the opposite of culture, but a site where culture is played out. ${ }^{3}$

This turn toward the body requires a new emphasis on space and spaces. Bodies are necessarily situated in space, and they bear the imprint of the spaces they are moving through and have moved through. Mediated by the body and its senses, different spaces become linked to different emotions. This relation is neither random, nor is it given once and for all: the connection between an emotion and a particular space can change over time, and the same spaces can trigger off vastly divergent emotions in various people. ${ }^{4}$

The aim of this article is to contribute some ideas about the ways through which emotions become linked to certain spaces. Starting from a discussion of the importance of material objects in shaping emotions, it will suggest temporalization as the central category to link materiality with knowledge and practices (1). The article will then touch upon the sources needed for such a project (2), before proceeding to a number of case studies related to the built environment of Delhi to show what such an investigation could look like (3), and finally draw some conclusions, again on a more theoretical level (4).

(1) Emotion studies' move toward the body has tended to displace language from its previously central position. Drawing on affect theory, a number of researchers have emphasized that bodies could be directly affected by objects without the necessary intervention of linguistic 
representation, thus giving a large place to reactions not mediated by consciousness. ${ }^{5}$ This approach might however hold the danger of replacing the dichotomy between nature and nurture by a no less unproductive one between the body and language or even between materiality and representation. I would like to suggest three ways of conceiving the interface between spaces, bodies and emotions, which might work to avoid these pitfalls.

First, a body's ability to be affected in a specific way by a specific space could then be seen as the result of a long-drawn process of the creation of emotion knowledge through experience and learning. This knowledge can be cognitive and conscious, but can also become habitualized and embodied. This allows for reactions that need not in every instance be the result of conscious and reflexive processes involving language. Language, experience, and embodiment are not temporally separate stages, but are imbricated. In turn, this does not mean that they merge and become indistinguishable - keeping them conceptually distinct has the advantage of opening up the investigation to processes of translation and mediation between them. Compared to affect theory and phenomenological approaches, which give space and its objects the agency to bring forth feelings, this allows the incorporation of cultural difference: different societies, in different times and at different places, but also different groups within the same society, can have different emotions in similar spaces because their minds and bodies have learned to be affected differently.

Second, spaces and practices co-produce each other. ${ }^{6}$ As cultural geographers have pointed out, space is not a natural given, but constituted through endowment with social meaning and constantly re-created through human practices, at both the interpretive and material level. ${ }^{7}$ Social interpretations, and to an even greater degree the material results of these practices, in turn create restrictions on future interpretations and practices possible for individual actors, thus making the experience of certain emotions more likely than others. Again, this can be a conscious process involving debates and language. However, this process also creates a material reality, which can have an impact without needing to recur to language at every single point in time. The material reality, again, is submitted to change, either materially or by reinterpretation.

Third, spaces can be endowed with an emotional valence through practices and experiences repeated over a long time. However, even a single and contingent event can become linked to space through memory. This link can be effected through personal memory, that is, for the individual or the social group who has lived through the event or events, but it can also involve memories transmitted over generations through knowledge and narratives. ${ }^{8}$

(2) These questions require us to probe new genres of sources. Written texts give information on how specific spaces were perceived, experienced, and interpreted and on how these creations of meanings were translated into practices. But historians also need to learn from geographers how to read maps ${ }^{9}$ and from art historians and experts in visual media studies how to make use of the visual archive, of paintings and photographs. ${ }^{10}$

What makes the interpretation of these sources so challenging is that they have to be read at two levels at the same time. Cultural studies have taught us to see maps and images as interpretations and as ways to create and enforce a vision of the world. Especially for the study of emotions, this approach opens up possibilities to access the way actors experienced and emotionally related to spaces - interpretations are less of interest for their own sake, but for the effects they bring about. However, if we are also interested in the materiality of space, in how bodies are sensually affected by the material structures through which they move, we need to read the same text not only for their spatial imagination, ${ }^{11}$ but also for what they tell us about this material reality. We have to ask whether the author of a map or a picture had access to the information he purported to pass on, and hence whether a certain building or street "really" existed at this time and in this shape.

(3) Shahjahanabad, known today as "Old Delhi", was laid out in 1639 as a planned city, next to the river and north of the ruins of former foundations. The image that pervaded the layout of 
the city at many levels was the garden of paradise. ${ }^{12}$ This held true for the city as a whole, but even more for the palace of the ruler and specifically for his private audience hall, inscribed by the Persian poet Firdausi's famous quote "If there is paradise on earth, it is this, it is this, it is this." 13 The contrast between the garden, watered by canals and the site of fruit-bearing trees, roses and carefully cultivated flowerbeds, and the wilderness, however, informed not only the layout of cities, but also became an image for the cultivation of the soul and its emotions as well: civility and virtue are not to be found in the immediacy of raw nature. Like the garden, the soul of a perfect man showed nature transformed into a work of art, into a carefully balanced harmony. ${ }^{14}$ These associations between gardens and a specific set of emotions were constantly re-invoked through the Quranic paradise-as-garden imagery, as well as through moral philosophy in the Aristotelian tradition. ${ }^{15}$ The garden was at the same time a metaphor for the cultivated soul, and also the space in which this cultivation and its emotions were learnt through sensory experience and performed through practices and courtly rituals.

However, the visual archive shows that this dichotomy between garden and wilderness, redoubling as an opposition between civility and barbarism in ethical texts, was only one part of the story. Three strongly emotionally coded scenes are typically depicted in the wilderness: hunting, a practice central not only for training those qualities of horsemanship and skillful use of weapons needed in battle, but also as a performance of masculinity; ${ }^{16}$ passionate love that transcends the boundaries of reason, famously depicted in the story of Laila and Majnun; ${ }^{17}$ and the encounter with Sufis and holy men, who embody the passionate search for the encounter with the divine. ${ }^{18}$ To a larger extent than hitherto, it is therefore necessary to view the city and the landscape, the garden and the wilderness, emotional restraint and unbounded passions together and to investigate seemingly contradictory emotional registers as part of an integrated, but by no means homogeneous, whole that encompasses a multitude of spaces in dialog with each other. Again: these miniatures provide us with a powerful entry to the way spaces and emotions are imagined, but they also point to practices by which bodies are exposed to and impacted by spatial arrangements and the emotional regimes associated with them.

How do these sources then translate into what we know about actual gardens and the practices associated with them? ${ }^{19}$ Research on Mughal gardens has largely focused only on the formal char bagh, the four partite gardens of the royal palace and noble mansions. However, Shahjahanabad knew different garden areas, each associated with distinct emotions.

Along the river, we find not only the famous gardens of the royal palace, but also the gardens of the richest nobles. These were the remnants of the classical gardens, more overgrown than during the height of the Mughal empire, but still very much in use, as evinced in the description of the daily visits of Akbar Shah in $1830,{ }^{20}$ and by the restoration and construction work that his son Bahadur Shah initiated. These riverside gardens were constructed on an elevated platform along the river and were characterized by the imbrication of outside and inside elements - gardens and pavilions opened into each other. Together with the location above the river and the extensive use of canals, spring fountains and marble, this allowed to keep the temperature down and to catch the breeze from the water. The imaginations of gardens as paradise went hand in hand with the construction of an environment geared to affect the body and the senses - the visual, obviously, but also the olfactory, the tactile, and the perception of temperature.

All activities except the public audiences and the most formal encounters took place here meetings between the king and his advisors, but also musical and poetical gatherings and the informal practices of sociability that accompanied them, such as performances of bards and dancing girls and religious festivities. While miniatures show that this area belonged very much to the restraint of the cultivated garden, the terraces regularly opened up to a background of landscape, which feature the river, at times teeming with crocodiles and sea monsters and villages and wild forests. ${ }^{21}$ 
The role of the objects in these paintings needs to be further explored. At the moment, it seems probable that they function as the link to the symbolism of poetry. The miniatures thus created a whole network of mutual references between material objects like for example the wine glass; their interpretation and imagination as symbols in the love poetry of the ghazal, where wine and the cup bearer are situated at the interstice between worldly and divine love; and the sensual practices and experiences associated with convivial drinking in the garden. Neither can any of these levels be understood without reference to the others, nor is it possible to posit a primordiality - temporally or logically - of either the imagination or the bodily experience for bringing forth specific emotions in specific spaces.

The third complex of gardens was situated in Mahrauli, a village some ten miles to the south of the city, which houses the shrine of the famous Sufi saint Qutb ud Din. As result of the Queen's vow to endow the grave of the saint with a flower cover every year, since the beginning of the 19th century, the entire court moved down to the orchards and artificial lakes of Mahrauli during the rains, accompanied by a large portion of the inhabitants of the city. The procession had a religious core, but it was also a celebration of the monsoon, and of the eroticism traditionally associated with the rains - one of the reasons why courtesans and athletes had a prominent place in the descriptions of the procession. ${ }^{22}$ While many of these gardens were public or semipublic, the family of the King had a summer palace of their own, which also contained gardens, and most famously, ponds and tanks in which the royal ladies could swim. The gardens, however, were not of the formal char bagh type as in the city, but built into the landscape and leading into the shady groves of orchards. ${ }^{23}$ The emotions associated with the outing to Mahrauli drew both on a long established temporalization of emotions - the monsoon as a time of erotic pleasure - and also on a spatial distancing from the restraints of city-life. The fact that the celebrations were repeated every year created an anticipation of the events to come, but also advance knowledge of the emotions to be encountered, built on personal memory - stored both in the mind and in the body - and on experiences shared through stories. This made the occurrence of the specific emotions linked to this time and space more likely - though of course by no means certain.

The layout of the city remained basically unchanged from the 17 th century to the middle of the 19th century. Emperor Shah Jahan, after whom the city was named, built the city wall, the royal palace, the Friday mosque, and two of the central throughways: Chandni Chauk, starting from the Western gate of the palace, and Faiz Bazar, starting from the Southern Gate. His nobles rapidly followed suit, dotting the cityscape with a multitude of palaces, reproducing the structure of the royal palace at a smaller scale, with mosques, gardens, and public buildings like caravanserais and dispensaries. This led to an imbricated structure of outside and inside, of more or less accessible spaces, of inclusion and exclusion. ${ }^{24}$ While the bazaars and thoroughfares permitted people and gazes to move freely, others areas, like the mazes of small lanes and the cul-de-sacs of the neighborhoods, were marked by high and windowless walls, and closed off from the outside world by a gate, which would be shut at night or in times of danger. ${ }^{25}$ This layout is both the result of a spatial imagination and assumptions about the link between spatial structures and moral virtues and emotions anteceding the actual building process, as also the material basis bodies had to negotiate in the centuries to come.

The division between accessibility and closing off is reproduced in 18th century maps and pictures. Two famous maps show a bird's perspective of Chandni Chauk and Faiz Bazar - this perspective, however, does not go beyond the main streets to the smaller lanes, nor does it extend to the depiction of the houses. These, in turn, are shown from the perspective of a man standing in the street, whose gaze does not penetrate beyond the outer surface. ${ }^{26}$ The same two-dimensionality that does not attempt to penetrate the façade of the houses and palaces is also at work in a number of depictions of nobles' palaces, probably drawn under French 
patronage in the 18th century. ${ }^{27}$ Maps thus can be read as both imaginations of space, but also as reflections and interpretations of actual day-to-day experiences of accessibility and its denial.

The British rule of the 19th century effected a profound change in these modes of perceiving and experiencing space. As the colonial gaze imagined itself unlimited, maps began to figure a homogenous bird-eye's view. This means that a map of the late 1840s, draw under the patronage of a British officer, possibly Thomas Metcalfe, not only showed all the lanes and bye-lanes, but also the interior structure of mansions and palaces, their walled-off gardens, and female quarters. In the years before 1857, this most probably did not reproduce any real access and knowledge of the cartographer, but nevertheless showed the extent of the colonial claim and the direction they intended to move - and did move after the uprising. ${ }^{28}$

How does this impact the way different people emotionally appropriate space? From the 18 th century onward, we have a number of texts extolling Delhi as a space of pleasure - from the travelog of a young noble from Hyderabad, who described the blessings Delhi received by the presence of so many saints, dead and alive, and became even more enthusiastic in depicting the venues of aristocratic sociability, the courtesans, dancers, and musicians; ${ }^{29}$ to Ghalib, Delhi's most famous poet, who wrote verses renouncing paradise, as its delights could never match the drunken walks of friends through the lanes at dawn nor the sound of the flute and the bustle of the taverns. ${ }^{30}$ This emphasis on Delhi as a space of blessing and of pleasure, linked to the encounter with its inhabitants, the living and the dead, gives away under the colonial influence to descriptions focusing no longer on urban feelings, but on dates and measurements. ${ }^{31}$

The labyrinth of small lanes and more specifically, the possibility of closing them off, also allows tracing how the same space can lead to very different emotions for different groups of people. While the British saw it as a space of resistance to colonial penetration and hence of danger and fear, most dramatically during the re-conquest of the city after the revolt of 1857 , for the inhabitants, the same architectural arrangement created feelings of security and trust. Matters came to a heed in the 1870s when the colonial power insisted on putting an end to the neighborhood gates and replaced them with a more costly and less efficient police system against the unanimous opposition of the citizens of Delhi, ${ }^{32}$ reminding us not only of the contested character of emotions linked to specific spaces, but also of the role of power in resolving these contestations and transforming spaces in a way to allow or disallow certain bodily movements and emotions.

Mapping the emotions evoked by different spaces, even for as restricted an area as the walled city of Delhi, would need an extensive research project. It would be necessary to take account of more differences, if we want to avoid slipping back to the notion of a universal body, affected by space and materiality in any simple and unequivocal way - the same narrow lanes, which created a feeling of security for elder men, might feel claustrophobic for their sons, while the pleasure experienced at a drunken stroll in Ghalib's time was definitely an emotion accessible only to men. It also needs to be explored how an investigation of spaces and their feelings can transcend a focus on the elite.

Furthermore, the historical change of emotions would need to be traced in greater detail. This refers to transformations of feelings and their interpretation in the longue durée - in which, for example, the Quranic garden imagery might lose importance, or at least cease to be linked to mundane gardens, so that the gardens lose their readability, even before they are transformed into different material spaces. But it also has to take into account the impact of events transforming the cityscape, as for instance the large-scale destructions effected in the aftermath of the re-conquest of the city in 1857, which for at least one generation of citizens of Delhi left a remembered layer of spaces below those actually visible to newcomers.

The example of the revolt of 1857 also shows the extent to which the same event can mark spaces with different very emotional traces. From the first moment that the news of the "mutiny" reached Britain, it created an unprecedented public and popular interest in information and first-hand accounts, which later became the basis for a whole industry of mutiny-memoirs 
and mutiny-fiction. ${ }^{33}$ These narratives not only held alive the memory of the events of 1857 , but also served as the basis for a discourse of difference, opposing oriental perfidy and treachery to British heroism and chivalry. ${ }^{34}$ In Delhi (as in Lucknow and Cawnpore, the two other iconic locations of the 1857), the narratives were inscribed into the space of the city, marking out "mutiny-circuits" with memories and memorials for British residents and even more for visitors and the increasing number of tourists. ${ }^{35}$ If the narratives endowed the spaces with expected emotions, the bodily and sensual encounter with the spot "where it all took place" reinforced the power of the narrative by backing it up with personal experience. Unlike British memories, the experience of the Indian inhabitants of Delhi - the three months of intense bombarding, the wholesale slaughter during the re-conquest and the deprivations brought about by the evacuation of the city, which lasted for almost two years - neither found venues for its expression, at least before the turn of the century, nor could it be embedded in rituals and practices. While individuals recollected the scenes of violence and connected them to specific places, this did not reach the collective memory, which though intense to this day remains strangely de-localized. Linking spaces and emotions through collective memory thus does not simply happen, but is the result of a power constellation, which privileges the past experiences of certain groups over others.

(4) What preliminary conclusions about the ways in which emotions and spaces become linked through time can we draw from these examples? How are emotional experiences and practices made possible and probable through building spaces? First: city planning aims at the creation of emotions, at least for those inhabitants of the city deemed important. This building of feelings into the cityscape is based on emotion knowledge specific to a certain time and place, as the link between garden and paradise has shown. Both the civilization and balancing of emotions and the ability for a ruler or nobleman to be able to enjoy the pleasures of the gardens, their interplay of culture and nature, as well as the events typically taking place in a garden, are central elements for the Mughal era. Planning and building creates a material reality, which enhances the probability of specific emotions, and thus stabilizes and perpetuates the emotion knowledge. Material reality and the emotion knowledge are intertwined and reinforce each other - integrating temporality allows looking at space both as a material reality and as the result of an antecedent and ongoing cultural interpretation.

Second: Both emotional experiences and emotion knowledge are open to change over time. The emotion knowledge once at the basis of the city's planning can be transformed or simply forgotten - few people walking through the Mughal gardens of Delhi today still know about their mystical underpinnings, and hence most probably experience quite a different set of feelings. In turn, new dominant emotions can lead to the transformation of material reality, as in the creation of wide open spaces in place of the narrow lanes between the Friday mosque and the palace after 1857, allowing for allaying British fears and playing up to their desires of visibility and transparency. Besides, the material reality of a city can also be transformed through events that do not have their origin in emotions - for example, the building of the railway right across the city of Delhi in the 1860 s, which effectively cut of its northern from the southern part - but which nevertheless can lead to the reconfiguration of the city's space, both material and emotional.

\section{Short Biography}

Prof. Dr. Margrit Pernau is a senior researcher at the Center for the History of Emotions at the Max Planck Institute for Human Development in Berlin. She studied History and Public Law and received her doctorate in 1991. In 2007, she was promoted to professor with a study on "Plural Identities of Muslims in Old-Delhi in the 19th century". Beside the history of emotions, her areas of interest include modern Indian history, the history of modern Islam, historical semantics, comparative studies, and translation studies. 


\section{Notes}

* Correspondence: Max Planck Institute for Human Development, Lentzeallee 94, D-14195 Berlin, Germany. Email: pernau@mpib-berlin.mpg.de

${ }^{1}$ For challenging discussions, I am very grateful to my colleagues Dagmar Ellerbrock, Benno Gammerl, Anne Schmidt, and Razak Khan. I thank Abhishek Kaikar for our many talks on the history and geography of Delhi in the 18th and 19th century and Anja Berkes and Rachel Johnson for their editorial assistance.

${ }^{2}$ Reddy, The Navigation; for the history of the debate and some suggestions to overcome the dichotomy, see Plamper, Geschichte und Gefühl.

${ }^{3}$ Scheer, 'Are Emotions a Kind of Practice'.

${ }^{4}$ Gammerl, 'Emotional Styles: Concepts and Challenges'. For the fast developing field of emotional geography, see Davidson et al., Emotional Geographies; Smith et al., Emotion and the journal Emotion, Space and Society, published since 2008.

5 Thrift, 'Intensities of Feeling'; Ahmed, 'Sociable Happiness'; Anderson, 'Affective Atmospheres'; Crang et al., Thinking Space. While these approaches arrive at results surprisingly similar to theories on the effect material objects could have on the formation of character and morality, which were at the background of much of 19th century town planning in Britain and British India (Glover, Making Lahore), they draw not on medicine and climatology, but on phenomenological approaches.

6 Reckwitz, 'Affective Spaces'.

${ }^{7}$ Lefebvre, La production; Harley, The New Nature.

8 Erll, Memory.

9 Casti, 'Towards a Theory'; Jacob, 'Towards a Cultural History'.

${ }^{10}$ Mirzoeff, The Visual.

11 See the elaborations on this concept by Glover.

12 Rustomji, The Garden; Moynihan, Paradise.

13 Blake, Shahjahanabad.

14 Wescoat et al., Mughal Gardens; Hussain et al., The Mughal Garden.

${ }^{15}$ See notably Gulistan and Bostan, the famous moral instructions by the Persian poet Sa'di (1190-1283), aptly named 'Rose Garden' and 'Flowerbed'. The next step will now be to look more carefully into the iconography of Mughal gardens, to bring out the visual cues linked to specific atmospheres and emotions and to relate them to their use in other media.

${ }^{16}$ Koch, Dara Shikoh.

${ }^{17}$ For a miniature of the encounter of Laila and Majnun outside of the urban space, see F. Chela's 'Layla and Majnun in the Desert' (1595) in Losty, Indian Book Painting, fig. 29, 36. Here, the violence of the passions is so strong that it impacts not only the bodies of the lovers, but also sets into motion the entire landscape.

${ }^{18}$ See the miniature attributed to Govardhan 'Prince et ascètes' (1630) in Musée de la musique (Paris, France), Gloire des princes, fig. 40,82 .

19 For the emphasis on practices in studying garden cultures, see Ali et al., Garden and Landscape.

${ }^{20}$ Pernau et al., Information, see entries for Mahtab Bagh and Hayat Bagh.

${ }^{21}$ See 'A Lady of Rank on a Terrace', in Bautze, Interaction, fig. 44, 179.

${ }^{22}$ For more details and sources, see Pernau, Ashraf, 34-8.

${ }^{23}$ It would be interesting to compare this to the earlier, pre-Mughal gardens; see Welch, 'Gardens that Babur Did not Like'.

${ }^{24}$ For a discussion how these distinctions crisscross the concepts of public and private, see Pernau, 'From a "Private" Public'.

${ }^{25}$ Ehlers et al., Shahjahanabad.

${ }^{26}$ Gole, 'Three Maps'.

27 Lafont et al., The French, 26-8 and 34.

${ }^{28}$ For a detailed discussion on the possible usages of this map and its partially imaginary quality, see Pernau, Ashraf, 169-177.

29 Khan, Muraqqa-e Delhi.

30 Bausani, 'Ghalib's Persian Poetry', paraphrase p. 81.

31 See Pernau, Ashraf, 154-62. While the creation of order has been associated with the disciplining of emotions and even their suppression, it would be tempting to investigate the emotional regime, which comes with order, the planning of space and time, and the rationalizing of the allocation of resources.

32 Ibid., 345.

33 Erll, 'Re-writing as Re-visioning'. 
34 Metcalf, Ideologies.

35 Goswami, " "Englishness",

\section{Bibliography}

Ahmed, S. 'Sociable Happiness', Emotion, Space and Society, 1/1 (2008): 10-13.

Ali, D., and Flatt, E. (eds.), Garden and Landscape Practices in Pre-colonial India. Histories from the Deccan (London: Routledge, 2012).

Anderson, B., 'Affective Atmospheres', Emotion, Space and Society 2/2 (2009): 77-81.

Bausani, A., 'Ghalib's Persian Poetry', in R. Russell (ed.), Ghalib, the Poet and his Age (Delhi: Oxford University Press, 1997), 70-104.

Bautze, J., Interaction of Cultures. Indian and Western Painting, 1780-1910. The Ehrenfeld Collection (Alexandria, VA: Art Services International, 1998).

Blake, S. P., Shahjahanabad. The Sovereign City in Mughal India 1639-1739 (Cambridge: Cambridge University Press, 1991).

Casti, E., 'Towards a Theory of Interpretation. Cartographic Semiosis', Cartographica, 40/3 (2005): 1-16.

Crang, M., and Thrift, N. (eds.), Thinking Space (London: Routledge, 2000).

Davidson, J., Bondi, L., and Smith, M. (eds.), Emotional Geographies (Aldershot: Ashgate, 2005).

Ehlers, E., and Kraft, T. (eds.), Shahjahanabad - Old Delhi. Tradition and Colonial Change (Stuttgart: Franz Steiner, 1993).

Erll, A., 'Re-writing as Re-visioning: Modes of Representing the "Indian Mutiny" in British Literature, 1857 to 2000 ', in A. Erll and A. Rigney (eds.), Literature and the Production of Cultural Memory, Special Issue of EJES (European Journal of English Studies) 10/2 (2006), 163-85.

Erll, A., Memory in Culture (Houndsmill: Palgrave Macmillan, 2011).

Gammerl, B., 'Emotional Styles: Concepts and Challenges', Rethinking History, 16 (2012): 161-75.

Glover, W., Making Lahore Modern. Constructing and Imagining a Colonial City (Minneapolis: University of Minnesota Press, 2008)

Gole, S., 'Three Maps of Shahjahanabad', South Asian Studies 4/1 (1988): 13-27.

Goswami, M., '”Englishness” on the Imperial Circuit. Mutiny Tours in Colonial South Asia', Journal of Historical Sociology $9 / 1$ (1996): 54-84.

Harley, J. B., The New Nature of Maps. Essays in the History of Cartography (Baltimore: Johns Hopkins University Press, 2001).

Hussain, M., Rehman, A., and Wescoat, J. L. (eds.), The Mughal Garden. Interpretation, Conservation, and Implication (Rawalpindi: Ferozons, 1996).

Jacob, C., 'Towards a Cultural History of Cartography', Imago Mundi, 48 (1996): 191-98.

Khan, D. Q., Muraqqa-e Delhi. The Mughal Capital in Muhhamad Shah's Time, C. Shekhar and S. M. Chenoy (trans.) (Delhi: Deputy Publications, 1989).

Koch, E., Dara Shikoh Shooting Nilgais. Hunt and Landscape in Mughal Painting (Washington D.C.: Smithonian Institution, 1998).

Lafont, J.-M. and Lafont, R., The French \& Delhi: Agra, Aligarh and Sardhana (Delhi: India Research Press, 2010).

Lefebvre, H., La production de l'espace (Paris: Ed. Anthropos, 1974).

Losty, J. P., Indian Book Painting (London: The British Library, 1986).

Losty, J. P., Delhi 360. Mazhar Ali Khan's View from the Lahore Gate (Delhi: Roli Books, 2012).

Metcalf, T., Ideologies of the Raj (Cambridge: Cambridge University Press, 1997).

Mirzoeff, N. (ed.), The Visual Culture Reader (London: Routledge, 2012).

Moynihan, E., Paradise as a Garden in Persia and Mughal India (London: Scolar, 1982).

Musée de la musique (Paris, France), Gloire des princes, lonange des dieux: Patrimoine musical de l'Hindoustan du XIVe au XXe siècle Paris: Cité de la musique, Musée de la musique, 2003).

Pernau, M., 'From a "Private" Public to a "Public" Private Sphere: Old Delhi in Comparative Perspective', in G. Mahajan and H. Reifeld (eds.), The Public and the Private: Democratic Citizenship in a Comparative Perspective (Delhi: Sage Publications, 2003), 103-30.

Pernau, M., Ashraf into Middle Classes. Muslims in Nineteenth Century Delhi (Delhi: Oxford University Press, 2013).

Pernau, M. and Jaffery, Y. (eds.), Information and the Public Sphere. Persian Newsletters from Mughal Delhi (Delhi: Oxford University Press, 2009).

Plamper, J., Geschichte und Gefühl. Grundlagen der Emotionsgeschichte (München: Siedler, 2012).

Reckwitz, A., 'Affective Spaces. A Praxeological Outlook', Rethinking History, 16 (2012): 41-258.

Reddy, W., The Navigation of Feelings. A Framework for the History of Emotions (Cambridge: Cambridge University Press, 2001). Rustomji, N., The Garden and the Fire. Heaven and Hell in Islamic Culture (New York: Columbia University Press, 2009).

Scheer, M., 'Are Emotions a Kind of Practice (and Is That What Makes Them Have a History)? A Bourdieuan Approach to Understanding Emotion', History and Theory 51/2 (2012): 193-220. 
Sharma, S., 'The City of Beauties in Indo-Persian Poetic Landscape', Comparative Studies of South Asia, Africa and the Middle East 24/2 (2004): 73-81.

Smith, M., Davidson, J., and Cameron L. (eds.), Emotion, Place and Culture (Farnham: Ashgate Publishing, 2009).

Thrift, N., 'Intensities of Feeling. Towards a Spatial Politics of Affect', Geografiska Annaler, 86/1 (2004): 55-76.

Wescoat, J. L., and Wolschke-Buhlmann, J. (eds.), Mughal Gardens. Sources, Places, Representations and Prospects (Washington D.C.: Dumbarton Oaks Research Library and Collection, 1996). 